\title{
Pause Greater Than Three Seconds by ECG Finding
}

National Cancer Institute

\section{Source}

National Cancer Institute. Pause Greater Than Three Seconds by ECG Finding. NCI

Thesaurus. Code C119251.

An electrocardiographic recording that demonstrates an $\mathrm{R}-\mathrm{R}$ interval that exceeds three seconds, irrespective of the underlying rhythm. 